\title{
INTEGRIDAD: RESPUESTA SUPERADORA A LOS DILEMAS ÉTICOS DEL HOMBRE DE EMPRESA*
}

\author{
Marcelo Paladino \\ UNIVERSIDAD AUSTRAL (ARGENTINA) \\ mpaladino@iae.edu.ar \\ Patricia Debeljuh \\ UNIVERSIDAD ARGENTINA DE LA EMPRESA (UADE) \\ pdebeljuh@uade.edu.ar \\ Paola Del Bosco \\ UNIVERSIDAD AUSTRAL (ARGENTINA) \\ pdelbosco@iae.edu.ar
}

\section{Resumen}

Los escándalos que han sacudido al mundo empresarial han puesto en evidencia la necesidad de volver a analizar los fundamentos éticos de la empresa. No basta un simple juicio negativo, es preciso reflexionar sobre las causas del derrumbe, porque también es válido aprender de los fracasos. ¿Qué falló para que esas empresas no cumplieran con su misión? ¿Qué pasó con los valores fundacionales de cada una de ellas? ¿Dónde fueron a parar las convicciones personales de los directivos, con su visión del futuro, con lo que podían aportarle al país, a la comunidad humana? La experiencia demuestra que no es suficiente proponerse buenas metas, algunos valores-guía, ciertas prácticas favorables al ambiente y a la sociedad. Es necesario que todas estas determinaciones surjan de una condición interior de las personas que permita darle a cada acción un sello distintivo. Se trata de que en el centro de las personas y de las empresas se encuentre la condición de la integridad. Este trabajo presenta la integridad como un concepto superador al de los valores y virtudes a los que se hace referencia habitualmente, por cuanto significa actitudes y capacidades de los directivos para abordar cabalmente su tarea.

Palabras clave: integridad, toma de decisiones, liderazgo, cultura corporativa, ética.

* Una versión anterior de este trabajo fue publicada en los Anales del VIII Congreso de la Asociación Latinoamericana de Ética, Negocios y Economía (Alene), llevado a cabo el 11 y 12 de agosto de 2005 en Valparaíso, Chile. 


\begin{abstract}
The various scandals that have shaken the corporate world have shown the need to analyze once again the ethic foundations of the corporation. It is not enough to issue a simple negative judgment; we must learn from failure and reflect on its causes. Why didn't these companies fulfill their missions? What happened to their fundamental values? What happened to the personal convictions of their general managers, with their vision of the future, with their contributions for the country and the community? Experience shows that it is not enough to merely propose worthy goals, guiding values or policies in favor of the environment and the community. It is necessary that all these propositions originate in the personal convictions of each individual, so that each action will have a distinctive, personal mark. Integrity must be found in the center of each individual and corporation. This paper presents integrity as a superior concept amongst the values and virtues which are normally mentioned; it implies that management must adopt the enabling attitudes and abilities they need to carry out their work properly.
\end{abstract}

Key words: integrity, decision-making, leadership, corporate culture, ethics.

\section{Introducción}

El mundo de los negocios y la opinión pública internacional han sido últimamente conmocionados por la estrepitosa caída de empresas prestigiosas como Enron, World Com, Parmalat, Tyco, Arthur Andersen, Ahold, entre otras. Se podría seguir sumando nombres a una lista de organizaciones que eran altamente confiables de acuerdo con los estándares con que suele valorarse el desempeño social de las compañías: preocupación por el medio ambiente, capacidad de innovación, tasa de crecimiento, política favorable al desarrollo de las personas y de las comunidades.

La sorpresa fue tanto mayor por cuanto las empresas que se derrumbaron gozaban de un respeto que iba más allá de toda duda en el ámbito específico de su actividad. Incluso, se podría afirmar que ellas mismas representaban un modelo por seguir, un espejo en el cual reflejarse.

Tal vez el impacto de estos hechos es mayor porque la empresa es hoy una ins- titución clave en la sociedad moderna y desempeña un papel relevante. Se trata de una institución cuya importancia va más allá de la creación de valor económico añadido, puesto que tiene una fuerte influencia en la cultura de la sociedad. Es la misma comunidad la que percibe a los dirigentes de empresas como líderes. Y esto es más válido cuando se trata de empresas multinacionales, cuyo tamaño y poder económico exceden, a veces, a los de muchos de los países del planeta. Los hechos sucedieron, además, en una época en que parece haber expectativas mayores acerca del rol de la empresa en la sociedad.

Al respecto es ilustrativo el caso de Global Compact, una iniciativa lanzada en 1999 por el secretario general de las $\mathrm{Na}$ ciones Unidas, Kofi Annan, para promover la responsabilidad social empresarial desarrollando los valores universales. El objetivo es satisfacer las necesidades socioeconómicas mundiales expandiendo los beneficios de la globalización y evitando sus efectos negativos, mediante la difusión y la convocatoria a que los em- 
presarios adopten nueve principios vinculados a los derechos humanos, los derechos del trabajo y el cuidado del medio ambiente. A través de esta iniciativa, las empresas multinacionales se comprometen a trabajar junto con las Naciones Unidas en pro de la sostenibilidad de los mercados y de la búsqueda de soluciones en las comunidades sociales.

En la misma línea, Michael Camdessus (1998), ex director gerente del FMI, planteaba que:

[...] somos nosotros, los que estamos a cargo de la economía, los administradores de una parte de esos beneficios de Dios: el alivio de la pena de nuestros hermanos y la extensión de su libertad [...] es la misión de ustedes, hombres de empresa, que tienen en sus manos la enorme responsabilidad de ser gerentes de la economía mundial.

Corporate citizenship, accountability, responsabilidad social de la empresa y otras expresiones similares manifiestan una misma preocupación: que la actividad de las empresas responda con toda su capacidad a las necesidades de las personas involucradas, ya sean empleados, directivos, inversionistas o destinatarios de los bienes y servicios producidos, así como miembros de la comunidad a la que la empresa pertenece o en la que actúa.

En síntesis, se espera que la empresa, a través de la actividad que le es propia, asuma un papel protagónico en la construcción de la sociedad. Esta tarea requiere que los directivos, ante las presiones económicas o de poder, sean capaces de dar respuestas consistentes, para lo cual deben ser ellos mismos coherentes en el nivel personal.
Lo mencionado líneas arriba con las «empresas modelo» ha puesto en evidencia la necesidad de volver a analizar los fundamentos éticos de la actividad empresaria. A la luz de los hechos, es claro que no basta un simple juicio negativo, sino que es necesario reflexionar sobre las causas del derrumbe, porque es válido también aprender de los fracasos propios o ajenos. ¿Qué falló para que esas empresas no cumplieran con su misión? ¿Qué pasó con los valores fundacionales de cada una de ellas? ¿Dónde fueron a parar las convicciones personales de los directivos, con su visión del futuro, con lo que podían aportarle al país, a la comunidad humana?

Seguramente es beneficiosa la reflexión acerca de los alcances del compromiso social de las empresas, que muchas veces había sido dejada de lado a favor de una visión restringida -economicista- de los negocios, que parecía así despojarse del carácter de acción humana. Sin embargo, el hecho de que muchas empresas hayan incorporado a sus agendas este tema, hayan asignado responsabilidades directivas o estén implementando políticas concretas, no garantiza que sea suficiente. No habrá resultados si no se pasa de las meras intenciones a la acción, de las palabras a los hechos.

La experiencia demuestra que no basta con que en el nivel directivo se propongan determinadas metas buenas, algunos valores-guía, ciertas prácticas favorables al ambiente y a la sociedad. Es necesario, además, que todas estas determinaciones surjan de una condición interior de las personas -que por reflejo también se convierte en un atributo de la institución-, que permita darle a cada proyecto, a cada decisión, a cada acción, un sello distintivo. Se trata de que en el centro de 
las personas y de las empresas se encuentre la condición de la integridad.

El objetivo de este trabajo es desarrollar el concepto de integridad como concepto superador con relación al de valores $\mathrm{y}$ virtudes al que se hace referencia habitualmente. Superador en cuanto significa, por parte de los directivos de las empresas, una actitud y una capacidad necesarias para abordar cabalmente su tarea.

Teniendo en cuenta el creciente interés por este concepto, tanto de los teóricos de la actividad empresaria como de sus protagonistas, es necesario definir qué se entiende por «persona íntegra» o por «accionar íntegro de una empresa». No se trata sólo de una búsqueda descriptiva de los distintos modos de comprender y definir el término, sino de un estudio acerca de las consecuencias de cada postura en la vida concreta de las personas, las empresas y las comunidades.

\section{Integridad personal y comunidad}

Para el desarrollo de este trabajo, consideramos importante comenzar por el significado del comportamiento íntegro de las personas para la sociedad. En particular, de qué manera la integridad favorece relaciones interpersonales sólidas y ayuda a construir el bien común. Estas aclaraciones servirán para ubicar su función en el contexto del uso responsable de la libertad y para detectar los obstáculos más frecuentes que impiden la asunción plena de esta condición, no sólo en el ámbito laboral, sino también en el ejercicio de la función pública y de la gestión del poder en general.

\subsection{Integridad y relaciones interpersonales}

El esfuerzo por alcanzar la dimensión de la integridad produce innegables efectos positivos en la vida de las personas en general y, especialmente, en la gestión empresarial. Frente a las exigencias laborales o sociales, que pueden impactar negativamente sobre las personas, y ante las múltiples presiones que dificultan la toma de decisiones, impulsando a los afectados en direcciones distintas, apostar por la integridad es disponerse a conciliar armónicamente el propio bien y el bien común.

Sólo quien está auténticamente ubicado en el centro de su vida, quien es íntegramente él mismo, o por lo menos apunta a serlo, puede tener una visión panorámica de su situación y decidir prudentemente, teniendo en cuenta todos los elementos relevantes, con el margen de autonomía necesario para elegir concientemente. Ser uno mismo, sin fisuras, quiere decir que la estructura de la personalidad está apoyada en un conjunto de valores coherentes, que entran en juego cuando se establece el orden de prioridades al momento de decidir y actuar.

La integridad apela a lo más profundo de la conciencia e impulsa a actuar en consecuencia con ella. Esta visión amplia, propia de la persona íntegra, es la única que ofrece garantía de acciones realistas, es decir, acordes a cada situación concreta, sin dejar de lado ningún aspecto y con el fin de elegir el bien por encima de cualquier otro beneficio personal.

Esta actitud vital aparece también reflejada en la comunicación de la persona: la integridad de quien se comunica hace que su palabra tenga valor, logra que lo 
que dice sea confiable y que se crea que cumplirá lo que promete, de tal manera que establece vínculos de seguridad para el futuro. No se trata aquí de atribuir una mayor capacidad para ver la verdad -que es imposible de alcanzar en su totalidad-, sino de la esencial transparencia de las comunicaciones de las personas íntegras: su punto de vista subjetivo es presentado con franqueza, reservando los aspectos que legítimamente deben ser guardados, pero sin ocultar ni deformar el resto del contenido.

La integridad en la comunicación es un pilar en la construcción de redes interpersonales confiables y es una condición para la cooperación entre los hombres. Sobre la base de la integridad, se edifica la reputación de la persona y, por reflejo, también la de las instituciones, cuando estas son lideradas según el criterio de la integridad. La buena reputación consiste en gozar del reconocimiento de los demás, fundado en la confianza, en la rectitud de sus intenciones, y avalado por una trayectoria de transparencia y de honestidad en sus acciones. Se trata de algo sumamente importante para una actividad en la que están involucrados muchos agentes, cuyos resultados pertenecen al futuro y, por lo tanto, no son conocidos.

El valor de una buena reputación ha sido puesto de manifiesto muchas veces en el management. Sólo gracias a ella se genera un movimiento de confianza que permite extender los propios proyectos en el tiempo, contando con la cooperación positiva de los demás y con su lealtad para llevarlos a buen término. Cuando no hay buena reputación o cuando esta resulta sólo una fachada, se va fragmentando el tejido social y surge la actitud de desconfianza y de sospecha. Un escenario así es altamente inadecuado para la asunción de riesgos de largo plazo y se tiende, entonces, a operar exclusivamente en función del corto plazo.

En conclusión, si no se valora la integridad como aspecto relevante para los individuos, no se puede trabajar eficazmente ni para el bien personal ni para el bien común. La importancia de esta condición constitutiva, que podemos caracterizar como valor central de la persona, se nota aún más a través de los efectos que produce su ausencia. La falta de integridad implica una grieta insanable entre lo que se dice y lo que se piensa, entre lo que se considera una conducta adecuada y lo que se termina haciendo, entre lo que es moralmente justo y lo que parece resultar de la presión de las circunstancias. Y así como la integridad es la resultante de una trayectoria coherente en la huella de los valores humanos, un único acto que la traicione es suficiente para anular la red de lazos que logró construir lentamente entre las personas. La pérdida de integridad o, directamente, su ausencia ataca el tejido mismo de la sociedad, socava la confianza, genera reacciones de defensa y alienta represalias. Es evidente que sin ella, cualquier organización carece de solidez.

Otro efecto resultante de la falta de integridad es la corrupción. A menudo se quiere encontrar una insostenible justificación a la corrupción, amparándose en la imposibilidad de confiar en los demás, sugiriendo que uno es corrupto porque no serlo representa una debilidad imperdonable en un mundo de mutuos recelos. Sin embargo, este efecto no es sólo coyuntural, sino que se instala definitivamente como estilo de convivencia y hay que intervenir enérgicamente en sentido contra- 
rio para erradicarlo, enfrentándose con valentía a los continuos embates de la presión del ambiente. Sólo después de revertir la situación de falta de confianza en las personas e instituciones, es decir, sólo después de una fuerte inversión inicial basada en la integridad, será posible establecer de nuevo las reglas de juego de una sociedad sana $\mathrm{y}$ justa.

Esto no quita que, tratándose de un bien difícil de conseguir, deba siempre ser cuidado, porque es fácil desintegrar la relación entre las personas y entre las instituciones, y esta pérdida tiene efectos deletéreos en la comunidad en términos de desconfianza, descreimiento y fragmentación.

Si se aplica todo esto a la empresa, es fácil deducir que si falla la integridad de las personas, de nada le sirven los valores proclamados en su carta fundacional, la reputación ganada en la sociedad, la confianza de los inversionistas, el supuesto respeto de los derechos humanos y del medio ambiente: una empresa no vale por lo que dice respetar, sino por lo que hace y por lo que hace habitualmente. Una buena fama se construye poco a poco, actuando coherentemente en una misma dirección, de tal modo que las reacciones frente a problemas emergentes son previsibles en el sentido de que no se espera ninguna actitud oportunista, desleal o dañina, si se diera el caso. La transparencia en las transacciones y la confiabilidad son causa y efecto de una conducta coherente, y son también espejo de una actitud fundamental para con la sociedad y con las personas, una actitud que se manifiesta como servicio al bien común.

\subsection{Integridad y bien común}

La empresa, como otras instituciones de la sociedad, tiene el gran objetivo (misión) de contribuir al bien común. Entendemos que el bien común es:

[...] un concepto ético que se refiere al bien de las personas y en relación con ellas, el conjunto de condiciones de la vida social que facilitan el desarrollo como seres humanos de quienes integran la sociedad. Dicho brevemente, bien común es todo aquello que contribuye al común desarrollo humano (Melé, 1996: 7).

Cuando la actividad empresaria es entendida, entonces, como contribución al bien común, importan no sólo los resultados inmediatos, sino también los efectos duraderos sobre las personas, el ambiente y la sociedad. Tener una actitud íntegra implica que la propia participación en la construcción de una sociedad más justa se apoya en la coherencia interior de las personas, en su panorama valorativo y en sus acciones. Sólo así se garantiza su capacidad de hacer frente a las dificultades que puedan presentarse, desde las presiones sectoriales hasta las circunstancias históricas adversas, porque la cohesión interior no presenta flancos débiles y es más difícil de erosionar o torcer.

En cambio, la falta de integridad es compatible con una multiplicidad de intereses que entran en colisión entre sí. Piénsese, por ejemplo, en quien quiere gozar de buena reputación social, pero no cree en los valores que la sociedad respeta o los considera demasiado «costosos». En consecuencia, cuando haya que enfrentar dificultades, la persona no estará en condiciones de mantener las apariencias y establecerá prioridades que claramente demostrarán cuáles son los valores en los 
que realmente se funda su conducta. Cuando esto sucede, la decepción es muy grande, tanto en el nivel social como en el nivel personal. De ahí que muchos, en esta situación, tratan de retardar al máximo la caída de la propia reputación, añadiendo a la falta de integridad también la hipocresía, el engaño, la deslealtad.

En estos casos, las personas y las empresas que lideran no tienen fuerza para sobreponerse a las dificultades, a las múltiples presiones y no pueden aspirar al respeto de la sociedad, a la confianza, al crédito. Así se refuerzan las acciones preventivas desleales y las reacciones de carácter ocultamente compensatorio, lo cual desarticula en breve tiempo el armado de lazos sociales y personales necesarios para el buen funcionamiento de la sociedad. Se entiende así que, en el marco inevitablemente complejo de la sociedad y de los entornos nacionales e internacionales cada vez más interconectados, la integridad de los actores es el único respaldo contra las enormes posibilidades de engaños y juegos desleales, que terminan en pérdidas gravísimas en tiempo, bienes materiales y también en capacidad de convivencia entre personas y países.

La falta de integridad va mucho más lejos y repercute más allá de la esfera de la actividad específica de cada empresa, impacta incluso en las reglas de juego de la sociedad. A esta situación compleja hay que sumarle que ni el marco legal ni las acciones de gobierno alcanzan por sí solas para lograr la integridad en las personas y en las empresas, porque la integridad constituye un modo de ser de cada persona. Por tanto, para alentar tal actitud fundamental habrá que apelar primero a una cultura familiar y a una cultura social que la instale como rasgo valioso. La di- suasión de las leyes y la acción de la justicia, si bien no son suficientes para el cambio cultural favorable a la integridad, son importantes para estimular a los menos convencidos a no intentar nada contra la cohesión social.

En definitiva, cuando una empresa es liderada por directivos íntegros, la vida en su interior se desarrolla con integridad y genera un efecto ejemplar en todos los que están involucrados en la actividad. En este caso se puede decir que la empresa es promotora de una cultura de la integridad, que irá reforzando actitudes y conductas, lo cual permitirá un desarrollo coherente de las personas y el enfrentamiento de las dificultades con mayor energía.

Sin duda, el concepto de integridad constituye uno de los pilares del cambio cultural en la sociedad. Una conducta íntegra genera confianza, pero también implica un equilibrio exigente para vivir los mismos valores en todos los ambientes y en todas las circunstancias. Y la realidad parece mostrar, en cambio, a empresas y directivos tironeados por criterios contradictorios al momento de tomar decisiones. Inclusive ocurre que quienes por integridad desean decidir sin violar aspectos éticos, parecen más vulnerables que los que no tienen escrúpulos al momento de decidir.

La importancia de la integridad para la construcción de una buena sociedad, hace necesario que definamos con precisión el origen y el sentido del término.

\section{Origen y sentido del término}

La sociedad parece ir descubriendo paulatinamente la importancia de la integri$d a d$, al menos por los problemas reales 
que plantea su ausencia. Los numerosos escándalos públicos relacionados con la corrupción ponen en el centro de la escena el valor de la integridad en las personas. Sin embargo, aunque mucho se hable de ella, parece haber cierta confusión acerca de los alcances del término. De ahí que sea preciso definir su significado y distinguir sus diversas acepciones.

El término integridad alude a una cualidad de todo ser que no carece de ninguna de sus partes. Muchas veces se toma como antónimo de la palabra «corrupto», que hace referencia a la pérdida de aquello que hace «completo» a alguien e implica, por tanto, alterar o trastocar la forma de alguna cosa. La palabra integridad sugiere la totalidad de la persona. Puede decirse, entonces, que sin integridad las personas no están propiamente completas como seres humanos. Así como se habla de número entero también se puede decir «persona entera», lo cual indica que no está dividida, que es la misma tanto en su vida privada como en su vida pública. Habitualmente se entiende como persona íntegra aquella que permanece fiel a sus principios sin importarle las consecuencias, que es auténtica, sin doblez en sus intenciones ni en su conducta, que obra siempre a conciencia y que no elude sus responsabilidades.

Ahora bien, estas expresiones dan cuenta de los variados significados que encierra el término integridad. Sin embargo, no llegan a explicar la naturaleza de este concepto. El origen etimológico de la palabra puede aclarar esta cuestión. En efecto, el vocablo integridad procede directamente del latín integer, formado sobre la base del prefijo negativo in más teger, conectado por su raíz con el verbo tango, cuyo sentido genérico es tocar, pero que en su acepción negativa significa herir, violar, golpear, contaminar, etc. Esta constelación de sentidos permite ubicar en su familia semántica el término integer y traducirlo como intacto, entero, incólume, genuino, sano, puro, honesto, imparcial, no contaminado, sin prejuicios, racional.

Es tanta la fecundidad del concepto integridad, que permite el traslado de un campo semántico a otro e involucra muchos aspectos de la existencia humana. Sin embargo, en todas sus acepciones, «ser íntegro» implica invariablemente la capacidad de desplegar las propias fuerzas no disminuidas. De ahí que, si se lleva este término al campo moral, hace referencia a la característica de las personas que actúan con justicia, tanto para consigo mismas como para con los demás. Así, el sentido moral del término «íntegro» aplicado a las personas subraya la incidencia positiva que tienen en el ser humano las actitudes, las decisiones y las acciones, de tal manera que, cuando estas son adecuadas a la situación concreta, es decir, cuando son prudentes o justas, completan debidamente a la persona. De esto se desprende que íntegro sea también sinónimo de persona recta, proba, intachable, sólida, sin fisuras, coherente. Por lo tanto, alguien puede ser definido como moralmente íntegro cuando por hábito actúa o se sitúa frente a la realidad de una manera respetuosa de la naturaleza de las cosas y de las relaciones entre ellas.

Para profundizar el concepto de integridad, consideramos necesario ahora analizar cómo esta interviene en la toma de decisiones (racionalidad), qué implica en el campo de la vida personal (comportamiento moral) y en la vida en sociedad (relaciones interpersonales). 


\subsection{Integridad y racionalidad}

Entre las acepciones clásicas del término íntegro se encuentran las de «sin prejuicios» y «racional». Considerando el proceso del conocimiento humano y su capacidad de pasar de lo conocido a lo desconocido, ya sea a través de los sentidos o del razonamiento, se entiende que es necesario identificar cuál es el requisito que permite pasar sin interferencias de las premisas -lo conocido- a las conclusiones -lo desconocido-, para que estas sean válidas y ciertas. La misma experiencia demuestra que cualquier consideración impropia, por ejemplo, una intervención indebida de las inclinaciones afectivas, como el miedo o el exceso de entusiasmo, la aversión a algo o la dependencia sentimental, podría torcer el proceso y falsear el resultado.

Se suele decir que a veces es necesario ser «fríamente racional», en el sentido de que ocasionalmente hay que tener en cuenta el recorrido lógico de algo para entender debidamente la cadena de causas y efectos. Con seguridad, no se trata de una expresión particularmente apreciada en la actualidad, porque nos encontramos en una atmósfera cultural más bien proclive a lo afectivo, como una manifestación más humana que lo puramente racional. Sin embargo, es innegable que lo afectivo de cualquier signo - positivo o negativo- no mejora la calidad del razonamiento, que es una operación con una mecánica propia, en la cual cualquier elemento ajeno representaría más bien un obstáculo y no una ayuda.

La racionalidad, por tanto, debe poder marchar sobre los rieles específicos de los nexos lógicos. Esto no significa que uno deba hacer abstracción definitiva de los otros factores que influyen en la toma de decisiones, sino simplemente que el razonamiento tiene una cierta autonomía en su desarrollo y que la integridad, es decir, la no contaminación de tal proceso, es garantía de la validez de los resultados. Por esta razón, es congruente darle el nombre de integridad a la capacidad de razonar sin la influencia de intereses o sensaciones particulares. Esta acepción, en definitiva, se refiere a la entereza necesaria para tratar de comprender algo más allá de las propias preferencias o temores.

Por otra parte, también puede hablarse de integridad en el razonamiento cuando nos referimos a la capacidad de observar el cuadro completo de los elementos que componen la realidad examinada: la visión íntegra garantiza el resultado del razonamiento porque cualquier parcialidad o negligencia en la consideración de lo relevante para componer las premisas repercute en la pobreza de las conclusiones.

\subsection{Integridad moral}

Analicemos ahora, desde otro ángulo, qué quiere decir la integridad aplicada al campo de la vida personal. Entendemos por persona íntegra aquella cuya conducta no la expone a todo lo que podría perjudicar o dañar su consistencia física, afectiva y psicológica. Su integridad es una garantía de estar al reparo de lo que atenta a la incolumidad. Podríamos pensar aquí en actitudes propensas a las adicciones, que con ligereza se despreocupan por los efectos en el largo plazo. Se puede también considerar como conducta no íntegra a la que implica irresponsabilidad en el campo afectivo o sexual, por la cual la persona no tiene en cuenta el respeto debido a los demás y termina dejándose llevar por sus impulsos. Su falta de integridad afec- 
tiva o sexual resulta ser, en última instancia, también un uso defectuoso de la libertad, porque no sólo se daña a sí mismo, sino que su acción puede repercutir negativamente en otros individuos. Por eso, la incolumidad que la integridad defiende no es sólo la de la persona, sino también la de todos los actores que entran en relación con ella.

En definitiva, el resultado de la pérdida de algún tipo de integridad es doble. La persona que no es íntegra pierde, por su conducta irresponsable, su potencial humano tanto en la individualidad como en la capacidad de establecer relaciones satisfactorias con los demás, y empobrece por esta pérdida no sólo su vida privada, sino también algún aspecto de la vida social.

Ser íntegro implica, además, mantener un mismo criterio valorativo para los múltiples frentes de la existencia de la persona, lo que elimina el efecto de fragmentación que produce el tener actitudes diferentes y, a veces, hasta diametralmente opuestas en la vida privada y en la vida pública, con algún grupo y con otro. En este sentido, es un hecho que el actual contexto laboral parece separar drásticamente los distintos aspectos de la vida de las personas y hace más difícil que mantengan su «integridad» psicológica y moral. Por otro lado, la fuerte exigencia en el mundo del trabajo y el marcado carácter competitivo de las funciones producen un endurecimiento de las actitudes y privilegian -por lo menos aparentementelos aspectos de la personalidad que no se inclinan por la comprensión ni por la tolerancia.

El gran desgaste que esto significa para las personas hace más necesario el des- canso en el hogar como un espacio totalmente «otro» respecto del mundo público del trabajo. Esta clara separación favorece la división interior de las actitudes para la vida laboral y aquellas que son apropiadas para la vida familiar o para la amistad. Las metáforas de la «lucha» o de la «jungla» para describir el mundo del trabajo fortalecen aun más el equívoco y marcan la clara separación entre los dos mundos: el de la vida pública y el de la vida privada, propiciando una verdadera «esquizofrenia»-en términos literales, mente dividida- en las actitudes de las personas, que se vuelven dulces y hasta frágiles con sus seres queridos y ásperas y duras con los demás. Esta separación interior no hace bien porque «desintegra» a las personas, les crea máscaras o personajes y origina que, con frecuencia, la verdadera personalidad quede escondida, relegada e incluso desaparezca entre tantos disfraces, con los consecuentes trastornos de identidad y de personalidad.

Por otra parte, si los valores de la persona que se manifiestan en su conducta son el sello de su personal estilo de vida, para que se trate de algo auténtico, es necesario que esos valores rijan todos los aspectos de la vida, tanto los privados como los públicos, en las relaciones familiares y en las laborales. Esta coherencia de actitudes sólo es posible cuando hay una convicción interior de que es bueno actuar según esos valores. Es desde el ejercicio «íntegro» de una personalidad, cuya forma son las virtudes, que es posible la intervención rica y fecunda en la vida propia y en la de los demás. En efecto, es precisamente este carácter de coherencia interior, es decir «co-herente»-palabra que también alude a la unión inseparable de todos los elementos que constituyen algo complejo-, lo que hace que cada parte se 
encuentre bien adherida a las demás. De esta mayor consistencia personal brota la capacidad para concebir buenas ideas y realizar acciones constructivas.

En un mundo compartimentado, como tiende a ser el nuestro, el esfuerzo por mantener la integridad es quizá mayor. Sin embargo, en esa misma medida es más necesario y más urgente porque lo que está en riesgo es el carácter humano del trabajo y de la vida en general. Nunca como hoy se habla tanto de la necesidad de evadirnos de la realidad, y nunca como hoy se dan tantas prácticas de evasión que son una verdadera pérdida de identidad, como pueden ser las adicciones en general o las diversiones que aturden y desatan las pulsiones en conductas fuera de control, desarticulando las personalidades. Hasta desde el punto de vista teórico, Jacques Lacan nos ha acostumbrado a renunciar al «sujeto» para quedarnos con el «múltiple», subrayando así la inevitable fragmentación del ser humano en sus distintos campos de batalla. Muchos hablan también de la huida de sí mismo como característica del ser humano de hoy. Pero de nuevo es posible encontrar la razón de estas fugas en la incapacidad de mantener integrados los aspectos y diferencias de la propia vida.

Antes se ha hecho referencia a la «lucha» o la «jungla» como metáforas para definir al mundo del trabajo o, en todo caso, el ámbito público. Estas ideas refuerzan un equívoco y, en especial, aquel que considera que otras y totalmente ajenas son las reglas del adentro y el afuera de la vida humana. No vamos a negar las obvias diferencias entre el hogar y el mundo, pero el sentido de la vida de una persona es tanto más intenso y significativo también para los demás cuanto más unifi- cada sea su personalidad. Que pueda ser ella misma en el mundo del trabajo y entre familiares o amigos es, sin duda, una ventaja que permite una sana integración de todos los aspectos de su existencia.

Por eso vemos positivamente todas las iniciativas que apuntan a reunificar a las personas, ofreciéndoles un clima cálido en el lugar de trabajo y un trato más personalizado en las relaciones laborales. Sin embargo, esto sería insuficiente, si no se tuviera como objetivo permitir integrar todos los aspectos de las personas a través de un trato cuidadoso, respetando tanto la humanidad de los que están cerca como la de los que están lejos.

En este sentido, ser íntegros significa actuar impulsados por esos bienes ideales conocidos como «valores», porque estos son inherentes a las personas, y en la medida que renunciamos a ellos, en mayor o en menor grado, nos vamos deshumanizando. En cambio, la realización de los valores es algo propio de la vida personal en su totalidad, no sólo en aspectos determinados, y es característica de la persona íntegra esa tensión por alcanzar la misma calidad humana en todos los frentes de su actividad, porque la realización de valores tiene la particularidad de completar tanto al que los realiza como a la comunidad. Basta pensar en la honestidad o la sinceridad: una persona sincera no solamente es mejor persona, más transparente y más confiable, sino que la presencia de este tipo de personas constituye un tejido social más apto para una vida humana satisfactoria.

Por eso, la integridad, esa fidelidad a uno mismo, en un marco de auténticos valores humanos, permite mantener una coherencia interior que es garantía de 
firmeza y también de confiabilidad, sin la cual ningún trato interpersonal es posible, salvo la prepotencia y el engaño.

\subsection{Integridad y sociedad}

La integridad es la base de la confiabilidad de la persona, porque garantiza la consistencia del sujeto que toma las decisiones y que se relaciona con los demás. Toda sociedad se basa en una cierta cuota de confianza recíproca, que lleva a coordinar las acciones a través de la comunicación. Puede decirse que sin confianza cada uno queda relegado al aislamiento de su individualidad. La vida humana comienza y es posible sólo desde la confianza. Basta con mirar a los niños para comprobar esto: su inmadurez los hace dependientes de acciones y palabras por parte de quienes los cuidan, hacia quienes va su confianza de una manera totalmente espontánea, como un mecanismo que garantiza su supervivencia.

También en la comunicación encontramos un ejemplo claro de la necesidad de integridad para establecer relaciones interpersonales válidas y fecundas: la mentira, la hipocresía y la impostación son obstáculos insuperables que operan produciendo división y fragmentación, no sólo en los núcleos de la sociedad sino en las mismas personas. La posibilidad de reconstrucción de un tejido social sano depende de la eliminación de todo lo que lo desintegra.

Así, se entiende que la integridad en lo social se refiere a la condición de estar plenamente «integrado» a las redes de relaciones entre personas y entre instituciones, de manera tal que la propia presencia fortalezca esos vínculos, los haga más consistentes y más aptos para cumplir los fines para los cuales se establecieron. La integridad personal es una garantía de funcionamiento de los nexos entre personas, entre funciones y entre instituciones. Cuando el espacio público no es cuidado en términos de la integridad, puede suceder que los miembros de una sociedad, en cualquiera de sus estamentos y en cualquiera de sus funciones, usen su poder para fines privados en vez de ponerlo al servicio del bien común para el cual fue concebido. Esta forma particular de abuso de poder se denomina «corrupción».

Es llamativa la relación de oposición que aparece también en la formación semántica de los términos integridad y corrupción. La integridad tiene como efecto una mayor consistencia de la persona en sí misma y produce una mayor cohesión social: los miembros íntegros de la sociedad fortalecen los lazos de la estructura y la hacen avanzar hacia el fin propio, el bien común. La corrupción, en cambio, en cualquiera de sus niveles, pero mayormente en los altos de responsabilidad social, interfiere sustancialmente con los fines de la sociedad y termina desintegrándola y rompiendo el sentido mismo de la organización. Esto se manifiesta en cualquier tipo de institución, empezando por la familia, la amistad, la educación, hasta llegar a las organizaciones productivas o de servicio, así como en la función de Gobierno. La influencia nefasta de la corrupción es tal que donde falte integridad personal, esta se va filtrando hasta desfigurar el sentido mismo de la convivencia humana.

Considerando que la empresa es una institución relevante para la sociedad, con capacidades propias no sólo para producir bienes o servicios, sino también para participar en la edificación de la 
comunidad, será interesante analizar de qué manera se tiene en cuenta la integridad en el campo de la dirección de empresas.

\section{Integridad y dirección de empresas}

El tema de la integridad ha despertado también el interés de los académicos de la dirección de empresas. Su íntima relación con el liderazgo hace que sea de vital importancia para todos aquellos que dirigen a otras personas. De hecho, muchos coinciden en que un líder con integridad tiene una firme noción respecto de quién es, de qué es lo importante para él y ha de contar con la habilidad y la fortaleza necesarias para mantener sus convicciones, aun ante presiones contrarias.

Ahora bien, en la revisión bibliográfica de la literatura acerca de la integridad, se evidencian distintas categorías de análisis que reflejan aspectos parciales de su significado. Algunos autores se inclinan a relacionar la integridad con la racionalidad, otros la ven como una dimensión personal y otros, a su vez, la analizan desde un ámbito social. Las siguientes páginas intentarán esclarecer esta cuestión desde la visión de la dirección de empresas.

\subsection{Integridad como racionalidad}

Entre quienes propician una vinculación entre integridad y racionalidad están Joseph Petrick y John Quinn (2000). Estos autores consideran que los líderes con integridad tienden a exhibir una unidad coherente de propósito y acción ante la complejidad actual, sin sucumbir a la inercia burocrática o simplista ni a una toma de decisiones irresponsable.
Por su parte, Werhane y Freedman (1997) consideran que la integridad puede ser definida como la calidad moral de la autonomía, tanto en el nivel individual como colectivo. Esta concepción es avalada por otros autores (Paine, 1997; Carter, 1996; Erikson, 1950), quienes desde sus estudios de filosofía y psicología vinculan la integridad con la conciencia y discernimiento moral, lo que ayuda a distinguir lo que es correcto de lo que no lo es. En este sentido, la decisión moral y la rendición de cuentas públicas llevan a resolver los dilemas, luego de un análisis de las justificaciones de la conducta y del compromiso moral. De este modo, se forja un carácter por el cual las personas se adhieren a sus principios y alcanzan una coherencia o autenticidad entre los juicios, creencias, expresiones y acciones. Así también se logra una armonía entre los principios y prácticas diarias, que expresan la sinceridad con que se mantienen las convicciones.

Dentro de este marco, Petrick y Quinn (2000: 15) afirman que la integridad puede ser definida como la capacidad individual o colectiva para la repetición del proceso de alineación de la conciencia, deliberación, carácter y conducta moral que demuestra el balance de juicio, mejora sustancialmente el desarrollo moral y promueve los sistemas de apoyo para la toma de decisiones morales. Como no es posible lograr esto sin una adecuada preparación, Petrick y Quinn sostienen que la capacitación de los empresarios y ejecutivos ya debe incluir la formación de la integridad, e incluso que este recurso debe ser considerado como una ventaja competitiva. En efecto, estos autores advierten que a menudo los empresarios y los directivos tienen una visión incompleta, sin fundamentos, de la ética de la 
empresa; de ahí su resistencia a implementar políticas éticas o a plantearse el desafío que implica desarrollar líderes con integridad.

En cambio, las personas dotadas de esta capacidad pueden responder con decisiones equilibradas a la complejidad moral y al conflicto de valores. Quienes carecen de integridad no tienen coherencia de finalidad ni de acción. Es más, muchas veces, su reputación, que constituye un capital, se erosiona, con lo cual se exponen a desventajas estratégicas.

Thomas Becker (1998) define integridad como lealtad a los principios y valores racionales en el actuar; es decir, la integridad implica ser una persona «de principios», que practica lo que dice, haciendo caso omiso a las presiones emocionales o sociales, y no permite que ninguna consideración irracional ponga en riesgo sus convicciones racionales. La integridad entendida en estos términos lleva al compromiso de actuar acorde con los principios y valores morales, justificados según la realidad, y en la medida en que el conocimiento aumenta, la persona debe estar dispuesta a cambiar. En la misma línea, Halfon (1989) entiende la naturaleza de la integridad como un compromiso consistente en hacer lo que es mejor, especialmente en condiciones adversas. Para eso hace falta estar genuinamente comprometido, tratar de esforzarse para ser conceptualmente claro, consistente lógicamente; estar muy informado de la realidad y evitar todo tipo de autoengaño.

Por su parte, Mc Fall (1987) sostiene que la integridad personal requiere que un agente se suscriba a un conjunto consistente de principios o compromisos y que, ante la tentación o desafío, los sostenga, dado que los considera la opción correcta. Para preservar la integridad moral y ser fiel a uno mismo, es necesario mantener el orden y la coherencia con los propios principios, así como aferrarse a ellos ante la tentación y las presiones sociales. En estas afirmaciones vemos perfilarse el carácter moral, no sólo racional, de la integridad.

En una posición que implica claramente una transición a la integridad como característica personal que abarque más que la mera racionalidad, se encuentra Sandra Waddock (2003). Esta autora lamenta el gran silencio en las escuelas de negocios con respecto a la integridad y sostiene que, actualmente, la capacitación de empresarios y ejecutivos está orientada a formar líderes con una limitada capacidad para pensar ampliamente en los impactos de sus decisiones sobre los stakeholders. En su opinión, hace falta una perspectiva más holística, que tome en cuenta a todos los factores involucrados en la actividad empresaria.

Para esta autora, la integridad se identifica con la capacidad de estar presente en el momento, de ser consciente de lo que se está haciendo y de cómo lo que se hace impacta en los demás. Sostiene que la ética está integralmente vinculada a la actividad gerencial y que no sólo hay que tenerla en cuenta a la hora de resolver dilemas. Si falta la consideración de la integridad, a menudo se margina la cuestión ética. Las presiones del momento y una visión estrecha de los negocios, concentrada solamente en las ganancias y en el retorno a los inversionistas, indican la necesidad de ampliar la colaboración. De ahí que una empresa sana no puede estar centrada sólo en los negocios, en el mercado, sino en todos los sectores involucrados. 


\subsection{Integridad como dimensión de la persona}

Un enfoque de la integridad más centrado en la persona, se encuentra en la posición de Alejo Sison (2003). Este autor filipino afirma que en el análisis actual de los agentes económicos se introducen distintas apreciaciones acerca del capital de la empresa. Nos encontramos así con el capital intelectual, emocional, cultural o el capital social, propio de individuos o grupos. Sin embargo, según Sison, cuando nos referimos al capital social no se sale de una ambivalencia moral, dado que este puede funcionar tanto para buenos propósitos como para fines mafiosos sin perder sus características. Por esta razón, es necesario aclarar el valor moral de los fines y propósitos de los empleados y de los negocios, como la creación de riqueza y el bienestar de todos (overall wellbeing podría traducirse también como bien común).

Para garantizar la moralidad de los fines se ha creado, tanto en el ámbito privado como en el público, una serie de iniciativas: códigos de ética, sistemas de estándares, capacitación ética y lineamientos para la creación de leyes anticorrupción. Todos estos esfuerzos apuntan a la institucionalización de la práctica de la integridad.

En otras palabras, más allá del mero respeto legal, la ética de los negocios necesita ser institucionalizada de tal manera que impregne también las prácticas aparentemente aisladas de los individuos, que de hecho forman parte de una más amplia cultura corporativa de una particular empresa $^{1}$ [Sison, 2003: IX; nuestra traducción (n. t.)].
La palabra integridad sugiere entereza y estabilidad de una persona, de la cual otros dependen. La integridad, al ser un capital moral, perfecciona al ser humano. «El capital moral es lo que hace buena a una persona como ser humano» ${ }^{2}$ (Sison, 2003: 31; n. t.). Etimológicamente, Areté (virtud, en griego) indica lo que es mejor para el ser humano. Y dado que el ser humano no alcanza su plenitud en soledad, la empresa calza perfectamente en lo que Aristóteles denomina polis, estructura humana organizada.

La actividad racional humana depende siempre de su finalidad. Ningún «medio» puede erigirse a «fin» de la vida humana. Así, dado que el dinero no puede ser otra cosa que «instrumento» para conseguir los bienes necesarios para la vida, su finalidad tiene que ver más con lo que un ser humano es o debe ser como plenitud de su naturaleza. Pero como su naturaleza lo hace un ser sociable, no es posible alcanzar la plenitud fuera del contexto de la comunidad. Por esa razón, Aristóteles considera que la «eudaimonía» (felicidad, literalmente la buena conciencia) consiste en la actividad perfectiva realizada en la polis. Por lo tanto, la felicidad sólo puede alcanzarse gracias a un esfuerzo común, es decir, gracias a la cooperación.

En este mismo sentido, si bien la virtud es en primer lugar algo propio de la persona, dice Sison, no es posible practi-

1. «In other words, beyond mere legal compliance, business ethics needs to be institutionalized in such a way that it permeates even apparently isolated individual practices, eventually forming part of a particular organization's wider corporate culture».

2. «Moral capital is what makes a person good as a human being». 
carla fuera de un contexto o una comunidad. Volviendo al tema de los distintos «capitales», queda claro para Sison que sólo la virtud es un capital que no puede nunca ser usado para el mal. «De todos modos, la diferencia fundamental entre la virtud y las otras formas de capital es que la virtud no puede nunca ser usada para el mal» $^{3}$ (Sison, 2003: 34; n. t.).

Con el concepto de capital moral como integridad se sale de la ambigüedad: se trata de un capital que lleva sólo a fines buenos, es decir, acordes con la naturaleza humana, considerada tanto en la individualidad como en las relaciones entre las personas.

Un carácter virtuoso procede del cultivo de hábitos virtuosos, los hábitos virtuosos son el resultado de la repetida realización de acciones virtuosas, y las acciones virtuosas brotan de las inclinaciones o tendencias de la persona de acuerdo con su naturaleza y su fin último ${ }^{4}$ (Sison, 2003: 35 ; n. t.).

Junto con Sison, otros autores, como Graham (2001) y Solomon (1999), consideran la integridad como una dimensión personal que se encuentra internamente relacionada con una gran cantidad de virtudes. La integridad requiere que las acciones y convicciones de una persona sean muy «suyas», lo cual demanda una cierta coherencia entre sus creencias, deseos, compromisos y acciones. Graham (2001).

3. «However, the fundamental difference between virtue and the other forms of capital is that virtue can never be used to wrong».

4. «A virtuous character comes from the cultivation of virtuous habits, virtuous habits result from the repeated performance of virtuous actions, and virtuous actions spring from person's inclinations or tendencies in accordance with his nature and final end». resalta dicha coherencia cuando afirma que es esencial para el individuo ese sentido de ser uno mismo, hasta el punto que para ser una persona de integridad debe haber algo que sea tan importante para el sujeto que de perderlo, se perdería a sí mismo. Para este autor, decir que una persona actúa con integridad, no implica admitir que esa persona es íntegra, sino que manifiesta únicamente un rasgo importante necesario para serlo. Ser una persona con integridad requiere más que ser constante y firme con los principios de conducta, ser sincera, de mente abierta, clara conceptualmente y consistente lógicamente. Requiere moral como confianza, lo cual es incompatible con un carácter defectuoso.

Para Solomon (1999), la excelencia en los negocios se alcanza partiendo de una concepción de la actividad empresaria íntimamente relacionada con los valores. Según este autor, los escándalos que han asolado al mundo empresario en los últimos años ponen de manifiesto que no se trata de imponer a los negocios unos valores que le son ajenos, sino más bien de replantear la necesidad de analizar los fundamentos éticos de la actividad empresaria $y$, concretamente, de la finalidad que se persigue. En efecto, para Solomon un grave malentendido ha limitado el fin de los negocios al simple resultado final, generalmente reducido a términos monetarios. Bajo este prisma, todas las demás consideraciones dejan de tener importancia, y ahí está precisamente el error.

Los negocios se relacionan tanto con la integridad como con las utilidades, y éstas significan poco si su costo sacrifica la integridad. (En otras actividades humanas esto se llama prostitución). Las compañías sirven a la gente y no a la inversa, y los 
valores y las virtudes son lo que hacen que la vida profesional resulte gratificante y significativa» (Solomon, 1999: xiv).

Solomon sostiene que una buena empresa es aquella que, además de ser rentable, proporciona un entorno moralmente gratificante, en el que las personas buenas pueden desarrollar tanto sus conocimientos especializados, sus aptitudes y habilidades, como sus virtudes.

Con mucha frecuencia, la forma de hablar y de pensar acerca de los negocios no refleja esa idea básica de que la vida empresarial es ante todo cuestión de civilidad, integridad, de cultivar virtudes. Y éstas incluyen no sólo las virtudes empresariales obvias, como el ahorro, la tenacidad y la astucia sino las virtudes cívicas y de urbanidad como la preocupación por los clientes, por los empleados y por la comunidad, la cooperación y la confianza, la justicia y la lealtad. Cuando los negocios se segregan del resto de las empresas humanas por medio de consignas tales como 'los negocios son los negocios', los cínicos proponen lo que sencillamente no es verdad. Los negocios no son 'sólo negocios'. No son autónomos, con su propia justificación, reglas y razón de ser. Son, en esencia, parte de la vida y las comunidades humanas (Solomon, 1999: 33).

La postura de Solomon, ahondando en las características naturales de la persona, que no puede desarrollarse plenamente si no interactúa en un contexto interpersonal, desemboca en la dimensión social de la integridad.

\subsection{Integridad como dimensión social}

Hemos visto cómo Solomon plantea que la integridad tiene, por un lado, un sentido personal y, por otro, un sentido públi- co, permitiéndonos encarar la tercera de las interpretaciones que la literatura especializada nos ofrece. Se trata de la dimensión social, que en este autor queda estrechamente ligada al desarrollo moral personal, dado que la persona no es una isla como la entiende el individualismo de tipo hobbesiano, sino que actúa ligada a los demás.

Para él, laintegridad no puede falsearse porque es, por su misma naturaleza, lo verdadero, lo que evita la fragmentación de las personas y el resquebrajamiento de la entereza moral. Se contrapone a la hipocresía y al oportunismo, que llevan a decir una cosa y hacer lo contrario.

Nuestro sentido público y personal de la integridad se integran dentro de una unidad ya que la congruencia exige algo más que fidelidad a una sola meta egoísta. También implica coherencia y respeto por los demás. Requiere fidelidad a uno mismo en medio de los demás y junto con los demás. La integridad implica ser 'fiel a uno mismo' y esto lleva consigo ser fieles a los demás. La integridad es precisamente lo contrario de usar a otras personas para conseguir los fines propios, pero también implica tener muy claro cuáles son nuestros verdaderos fines (Solomon, 1999: 41).

Más allá de los cambios y vaivenes que puede haber en la vida, la integridad resulta esencial para llevar adelante una vida coherente. Es ver la propia existencia como una totalidad, como un carácter coherente y virtuoso.

Por tanto, la integridad requiere no solamente tener en cuenta los principios morales de cada persona, sino también preocuparse genuinamente por el bienestar de los demás individuos. De ahí que la integridad tenga además una dimensión 
social, que ha sido puesta de manifiesto por varios autores. Así, por ejemplo, la persona se encuentra constituida por el grupo del cual forma parte [Hampshire (1989), Solomon (1992), Taylor (1989)] y la conservación de la integridad requiere que el individuo cumpla con sus compromisos con varios grupos sociales, los cuales en cierto sentido constituyen el propio ser. May (1996) va más allá, al considerar que la integridad es la responsabilidad social hacia la comunidad y sociedad. El compromiso moral es el cumplimiento de una responsabilidad ética que tiene una fuerte orientación social, de manera que la persona de integridad moral se mantenga fiel a sí misma por virtud del reconocimiento e incluso, a veces, aplazando el compromiso con los otros.

Para Benjamin (1990), toda persona se encuentra rodeada de conflictos, de compromisos y de emociones, y la integridad la lleva a que pueda cumplir con su objetivo de vivir una vida buena, óptima, integrada, en conjunción con aquellos a quienes ve como iguales y cuyos compromisos, valores y principios siempre son considerados como propios. En estos casos, los individuos pueden entender que cuando se presentan diferencias morales, sus reclamos deben ser balanceados con las demandas morales legítimas de los demás. Para aceptar una decisión o enfrentar una situación, aunque no se reflejen los propios valores morales, cada persona debe alentar la integridad, entendida como un proceso en el cual la decisión tomada fomenta el entendimiento y respeto mutuo, y evita los conflictos con los demás.

De ahí que, siguiendo a Cheshire Calhoun (1995), puede decirse que si bien la integridad es importante para la persona, también la ayuda a pertenecer a una co- munidad y es, en ese sentido, una virtud social. Los principios que una persona apoya, de alguna manera, se trasladan a los demás miembros de la comunidad, lo que determina qué tipo de vida vale la pena vivir y qué tipo de acciones conviene realizar para alcanzarlos. Una persona con integridad se sabe parte de una comunidad y reconoce lo meritorio de esa comunidad. En la misma línea, Burbules (1992) sostiene que las virtudes son propiedades sociales que refuerzan nuestro carácter e integridad a través de la comunicación interpersonal y las relaciones con otros.

\subsection{La búsqueda de la integridad en la empresa}

Consideramos que el repaso hecho hasta aquí indica la preocupación por explicitar la importancia de la integridad para la vida de la empresa. Sin embargo, nos parece relevante plantear que hay algunas técnicas de dirección en las que subyace la búsqueda de integridad como factor clave para el desarrollo de la empresa y de la sociedad, como los códigos de conducta, la calidad total y la responsabilidad social de la empresa. Cuando se analizan en profundidad estas herramientas, resulta evidente -aunque no de una manera explícita- su relación con el comportamiento íntegro de las personas.

\section{a) Códigos de conducta}

En primer lugar, el auge de la ética empresarial se vio reflejado en la proliferación de códigos de conducta que de alguna manera intentaban alcanzar esta tan ansiada integridad, a partir del cumplimiento de los parámetros establecidos. A través de estos documentos formales, se intenta poner de manifiesto el interés de la alta gerencia de estandarizar las deci- 
siones que tienen repercusiones éticas. De algún modo, depender de ciertas normas lleva a los gerentes a ocultarse detrás de un código, creyendo que su conducta es ética si no viola las reglas establecidas. Sin embargo, esta visión legalista de los códigos se ha mostrado insuficiente, porque ha pretendido lograr una integridad impuesta desde afuera y que no responde a una identificación personal con los valores incluidos en el código.

Detrás de esta postura lo que subyace es una visión normativista de la ética, que la reduce a una de sus dimensiones: las normas, desgajándolas del logro de los bienes humanos y del desarrollo de las virtudes. Las normas, cuando son consideradas imperativos a priori, sin referencia a unos bienes objetivos ni a la adquisición de las virtudes, se convierten en meras imposiciones porque se les ha despojado de su contenido y de su relación con la verdad sobre el bien y sobre la persona. Con frecuencia, esta tendencia se puede apreciar en algunos códigos de ética empresariales que ponen demasiado énfasis en las limitaciones al comportamiento y en un cumplimiento formal, dejando de lado todo el valor que una norma encierra en sí misma.

No es extraño, entonces, que una persona cumpla con el código de ética sólo por un estricto sentido del deber. En tal caso, el fin de su acción es ajena a ella misma y, por tanto, no es expresión de su libre perfección, sino más bien del sometimiento a una ley externa y a veces, incluso, lejana. Una imposición desde afuera impide también que una norma se convierta en parte del carácter individual, porque no se asume como algo propio y querido. De ahí que, con facilidad, esto sea fuente de conflictos entre los valores individua- les y los de la empresa. Hursthouse (2000: 135) sostiene que cuando una persona actúa en contra de sus más profundas convicciones, deja de obrar virtuosamente porque se siente presionada por el miedo a la norma exterior. Lamentablemente, esta apreciación subyace en muchos individuos que ven al código de ética como una obligación externa, en ocasiones, sin sentido. De ahí la oposición que suele encontrarse a la hora de acatarlo.

Un código de conducta planteado en estos términos necesariamente generará cierta resistencia interior y quedará reducido a una actitud rígida, donde cada uno se refugia y cumple sin comprometerse. Por este camino de la mera obligación, no es extraño que se caiga en posturas estrictas, inhumanas, que forjan personas tiesas, acartonadas. Se convierte así a los códigos de ética en una larga enumeración de obligaciones, muchas veces pesadas e incomprensibles, en un ambiente en el que no se respira vitalidad y en el que la libertad no encuentra acomodo.

La misma realidad indica que no es posible acuñar normas para todo; por lo tanto, si bien es importante contar con ellas, queda claro también que no son suficientes. Las normas son buenas y perfectivas del hombre, en la medida en que lo guíen en la elección del bien, pero por sí solas no bastan para que las personas sean buenas. Hace falta complementarlas con los bienes y las virtudes. En consecuencia, una visión integral de los códigos propone integrar armónicamente en ellos estas tres dimensiones de la ética (Debeljuh, 2004: 86).

\section{b) Calidad total}

Puede decirse que el mayor impacto de un buen código de ética es crear las bases 
de una cultura corporativa fundada en valores. No hay que olvidar que cuanto más ética es la cultura de la organización, más éticas serán las decisiones de los individuos que la componen. En consecuencia, los esfuerzos por fortalecer la conducta ética de los empleados deben realizarse en el nivel institucional, con énfasis, entre otras cosas, en crear una cultura empresaria que promueva y aliente el comportamiento ético y que permita a los empleados expresar sus preocupaciones. En este sentido, los programas de calidad total facilitan el desarrollo de una cultura empresaria que promueve el comportamiento ético y que, por lo tanto, favorece la integridad en las personas.

En efecto, trabajar en un entorno que se caracteriza por un estilo de gestión cooperativo, que alienta la participación de las personas en el diseño de una cultura compartida, es más propicio para promover el comportamiento ético y la integridad. Los programas de calidad total fomentan ese sentido de comunidad en las organizaciones, con potencial para que la empresa y sus empleados sean más conscientes de las responsabilidades éticas.

La implementación de la calidad total se ha convertido en la última década en un auténtico fenómeno y, en la actualidad, constituye el modelo de cambio organizativo más utilizado en el mundo empresarial. Esta filosofía de gestión -que surgió a principios de siglo en los Estados Unidos- tiene un marcado enfoque dinámico y multidimensional; concibe a la empresa como un sistema abierto en constante relación con proveedores, clientes y otros stakeholders; y se apoya en unos principios básicos mayoritariamente admitidos por todos.
Numerosos autores coinciden en que las técnicas de calidad total pueden utilizarse para desarrollar una cultura empresaria sensible a la ética, que respalde y aliente la conducta moral en el lugar de trabajo y favorezca el desarrollo de la integridad en las personas.

El modelo de calidad total está también muy relacionado con el concepto de responsabilidad social de la empresa. En efecto, la calidad total adopta una definición muy amplia de la palabra «cliente», que incluye no sólo a los consumidores tradicionales de productos y servicios, sino también a los empleados de la empresa (cliente interno) y al resto de las personas que (directa o indirectamente) se ven afectadas por el producto o servicio. El reconocimiento de la existencia de múltiples partes interesadas trae consigo ciertas responsabilidades éticas que quizá no resulten fácilmente evidentes. Entre ellas, cabe mencionar las obligaciones con las comunidades afectadas por fusiones y adquisiciones (que pueden generar despidos), las responsabilidades frente a los consumidores acosados por la publicidad de productos peligrosos -cigarrillos, por ejemplo- y las responsabilidades frente a los países afectados por la presencia de empresas multinacionales.

\section{c) Responsabilidad social de la empresa (RSE)}

Detrás del concepto de responsabilidad social de la empresa se encuentra la intención de sensibilizar a las empresas respecto del papel que les compete desempeñar en una sociedad. De alguna manera, al plantearse el compromiso de la empresa con todos sus stakeholders se propone un nuevo modelo de organización empresarial que requiere repensar la 
gestión en términos de riqueza compartida y sostenible. El concepto de RSE apunta a generar un nuevo concepto de la rentabilidad de la empresa y tiene que ver con una visión de más largo plazo que incorpora la ética en los procesos de toma de decisiones y el respeto a las personas, aspectos íntimamente relacionados con la integridad.

La RSE está unida a la manera de entender la empresa como un lugar de desarrollo de todas las personas que se relacionan con ella. Es decir, la empresa, desde su estrategia corporativa, asume el compromiso de educar en el bien, de promover el bienestar, de otorgar a la sociedad un valor agregado; y se compromete a que esas acciones y esos beneficios perduren en el tiempo.

Básicamente, su aporte se centra en asegurarse de que en la toma de decisiones no prime únicamente el criterio economicista -que de hecho ha de estar presente en cualquier decisión empresaria-, sino el de ayudar a conciliar los diversos intereses con el fin de incluir los criterios sociales y éticos. De alguna manera, su tarea implica velar para que el compromiso responsable de una empresa, además de crear valor para el accionista, cree valor también para todos los que se relacionan con ella: para el cliente, atendiendo a su demanda, ofreciendo precios competitivos y bienes y servicios de buena calidad; para los proveedores, pagando precios justos por sus productos o servicios, sin abusar de los vaivenes del mercado; para los empleados, preservando y creando empleo, pagando salarios justos, y fomentando la estabilidad y la motivación laboral; para las generaciones futuras, cuidando que la actividad de la empresa no impacte negativamente en el medio ambiente.
Una empresa socialmente responsable es aquella que lleva adelante un negocio rentable y que asume también todos los efectos ambientales, sociales y económicos que genera en la sociedad. La manera en que cada empresa incorpora a su estrategia corporativa la responsabilidad social varía. Las diferencias dependen de factores como el tamaño, el sector, la cultura y, por sobre todas las cosas, del grado de compromiso de la alta gerencia. Del mismo modo, las acciones voluntarias que las empresas realizan dentro del marco de la responsabilidad social son muy variadas: desde las donaciones y contribuciones filantrópicas hasta la creación de fundaciones empresarias y alianzas con ONG, pasando por las campañas de márketing con causa social y los programas de voluntariado corporativo para sus empleados.

Todas estas iniciativas, y muchas otras más, apuntan a canalizar esfuerzos y articular acciones tendentes a lograr una mayor participación de las empresas en la sociedad. A su vez, estas acciones potencian el compromiso de los empleados con su propia empresa, fomentan la creatividad e innovación en ellos, y contribuyen a aumentar la motivación. De hecho, de nada serviría que una empresa demostrara un fuerte compromiso con los consumidores o con sus proveedores si no se preocupara por su primera responsabilidad social: el desarrollo integral de sus propios empleados. Concretamente, el campo de la relación empresa-familia estaría indicando cómo se enriquece la acción de la empresa.

Estos distintos enfoques de la dimensión no económica de la actividad empresaria y del liderazgo enfatizan la importancia del tema de la integridad, al mismo tiempo que revelan la dificultad para lle- 
gar a una definición coincidente del término. Cada postura ilumina un aspecto de la integridad, dejando de lado otras características que, sin embargo, resultan imprescindibles cuando se trata de vivirla. Por otro lado, además de alcanzar una definición más completa de integridad, es importante también, identificar las principales dificultades a las que están sometidas las personas que quieran vivirla. En el proceso de formación de dirigentes de empresa, debería resaltarse la presencia de enormes presiones que juegan en contra de la integridad en el momento de tomar decisiones.

Nos dedicaremos en el siguiente apartado a completar el concepto de integridad desde una visión más abarcadora de la persona y de la sociedad, así como a poner en evidencia ciertas dificultades que suelen presentarse a la hora de intentar ponerla en práctica.

\section{Importancia de la integridad y dificultades para vivirla}

\subsection{Relevancia del tema}

A través de lo analizado en las páginas precedentes, podemos afirmar que hay un nexo directo entre la condición de la integridad personal y la creación de confianza en el entorno. El círculo de confianza será tanto más amplio cuanto más constantes y prolongadas sean las actitudes y las acciones íntegras de personas e instituciones. Lamentablemente, también es verdad el caso contrario: cuanto más frecuentes sean los actos de corrupción, tanto menor será el marco de confianza entre las personas y en la sociedad en general, y tanto más prolongado será el efecto negativo.
Lo mismo puede decirse de las instituciones que están envueltas en un clima de desconfianza y son sospechosas de prácticas corruptas, pues no podrán revertir esa percepción social sino a través de un muy prolongado esfuerzo colectivo de integridad personal e institucional.

Uno puede preguntarse por qué lo único que sucede automáticamente y con una vertiginosa rapidez entre las personas es la pérdida de la confianza que está en la base de la sociedad, cuando la reconstrucción de la confianza es un proceso difícil y muy lento. Quizá la respuesta sea que las personas nacen con una predisposición para confiar en los demás, dado que no sería posible su misma supervivencia sin esa confianza instintiva. Por ello, la pérdida de la confianza en los demás no es una reacción automática o arbitraria, sino el resultado lógico de la pérdida de algo debido; esto es, de la posibilidad de creer que tienen las personas.

Lo que empeora la situación son las otras pérdidas conexas con la falta de confianza, como la imposibilidad de una comunicación satisfactoria entre las personas. Así, la persona que obra de manera corrupta no manifiesta a los otros sus intenciones, para poder aprovecharse de las reglas de juego de un entorno no corrupto. Por eso, cada acto de corrupción implica también engaño y falta de transparencia, con el consecuente efecto de romper los vínculos entre los miembros de una comunidad, y con el terrible corolario de hacer más difícil la reconstrucción del tejido social.

Cuando se empieza a descubrir que lo que dicen los demás no corresponde a lo que piensan o a lo que hacen, ni a lo que deberían hacer, se les deja de ver como 
aliados naturales. También la comunicación con ellos abandona lo que se llama el «pacto comunicativo», que nos hace esperar que el que dialoga sea sincero. Sin ese tácito pacto entre las personas es mucho lo que se pierde, y así como es rápido el camino del alejamiento y la desconfianza, es en cambio lentísimo y muy costoso el camino inverso. Uno de sus efectos inmediatos es la imposibilidad de cooperación leal, porque para construir algo en conjunto también debe existir un pacto tácito de colaboración para conseguir un fin común, y ese pacto se basa en compartir valores. Cuando la red confianza se ha quebrado, no hay valores comunes, porque la desconfianza produce fragmentación social y hace que las personas se retiren en un cerrado individualismo.

Para devolver a la comunidad su función, es necesario reconstruir las redes de confianza entre las personas. Una parte del trabajo de reconstrucción consiste en desarticular las estructuras de corrupción que funcionan en la sociedad. La mayor presión en esta lucha procede de la sensación de que todo está corrompido de tal manera que no es posible reaccionar. La lucha contra la corrupción empieza desde la convicción personal de que cada vez que se resiste a las presiones externas que impulsan a actuar de manera no transparente y desleal, se está positivamente construyendo un ámbito de vida y de trabajo más digno del ser humano.

A la luz de una realidad marcada por los efectos destructivos de la pérdida de confianza, y teniendo en cuenta el costo personal e institucional que deriva de la falta de un entorno de transparencia y lealtad para llevar a cabo las actividades conjuntas de los distintos actores sociales, queda puesto de manifiesto la relevancia de la búsqueda de la integridad. Por eso, la literatura especializada hace eco insistentemente de esta necesidad, aclara su alcance y propone estrategias para favorecer actitudes y conductas, aun frente a las presiones de lo urgente e inmediato, que parecen sugerir atajos hacia los resultados deseados.

\subsection{Dificultades para vivirla}

En primer lugar, parece existir una dificultad real para coincidir en una definición de integridad en la que converjan los distintos enfoques. En la revisión de la literatura sobre el tema de integridad, hemos podido reconocer distintas interpretaciones del término, cada una con el mérito de poner en evidencia ciertos aspectos de la integridad pero, al mismo tiempo, con la dificultad de no poder considerar simultáneamente todas las dimensiones y alcances.

Por otra parte, en técnicas de dirección de empresas, como los códigos de conducta, el TQM o el CSR, subyace la búsqueda de integridad de las personas como constitutivo de la empresa. Ahora bien, el análisis realizado hasta aquí revela que si bien el desarrollo de códigos de ética, los programas de calidad total y el compromiso por la responsabilidad social de la empresa pueden ayudar a fomentar la integridad de las personas, muchas veces se han mostrado insuficientes porque este tema se ve como una consecuencia aleatoria que de ninguna manera constituye el objetivo central de estas políticas.

Finalmente, respecto a la integridad y la formación de directivos, en los trabajos de Waddock (2003) y Solomon (1999), entre otros, se pone en evidencia el grave déficit de formación en temas de integri- 
dad personal e institucional, que procede sobre todo de no atender suficientemente la complejidad de la realidad del mundo de los negocios y de la realidad en general. Las escuelas de negocios y la academia, a menudo, dan la ilusión de que los problemas que se presentan sólo deben ser sometidos a la técnica adecuada para ser resueltos, sin que esto implique una decidida toma de posición de los protagonistas en un sentido o en el otro de la solución propuesta. Si solamente se trata de la aplicación de técnicas $-y$ con esto no se quiere despreciar lo que le debemos a la técnica-, se corre el riesgo de despersonalizar la instancia de la toma de decisiones.

También Petrick y Quinn (2000) advierten sobre la dificultad de integrar los distintos aspectos del management y las diversas perspectivas éticas que nos ofrecen las escuelas. Sin embargo, al mismo tiempo, muestran como indispensable la integración de las visiones y de las actitudes, porque no ser imparcial no nos permite acercarnos a la realidad eficazmente. Si bien su planteamiento no parece alcanzar la esfera personal de la integridad, su advertencia igualmente es útil para identificar otras aristas más de la complejidad del escenario.

En un esfuerzo por integrar las distintas visiones sobre liderazgo, Badaracco y Ellsworth (1989) proponen tres ámbitos altamente significativos para hacer frente a la complejidad de la tarea directiva: las convicciones y los valores personales, las metas de la organización y la conducta individual. A través de las conversaciones con los CEO de distintas empresas, los autores llegan a definir que los conflictos y los dilemas que se presentan a los directivos exigen de ellos actitudes de inte- gridad. Esta se entiende, principalmente, como la integración de las tres filosofías del liderazgo; es decir, del liderazgo político, del liderazgo directivo y del liderazgo por valores.

La búsqueda de integración se torna crucial porque cada filosofía del liderazgo implica un paquete de soluciones diferente y contradictorio respecto de los otros, a tal punto que las posibles alternativas representan verdaderos dilemas: precisión o flexibilidad; top-down o bottom-up; sustancia o proceso; confrontación o negociación; tangibles o intangibles. Evidentemente, cada filosofía tiene asumida una determinada concepción del ser humano y de la organización que pretende ser completa, y desde ahí orienta las acciones y establece las prioridades en los objetivos.

Badaracco y Ellesworth (1989) consideran que la integridad consiste en buscar el modo más eficaz de responder a las presiones del momento, porque no nos limitamos a aplicar sólo uno de los criterios, sino que, mediante la integración de las visiones, enfrentamos la complejidad de la realidad con un mayor número de herramientas, sin privarnos de los beneficios que cada postura ofrece.

Sin embargo, no basta esta integración externa de herramientas operativas para que sea eficaz el liderazgo. Es necesario que el líder busque la integridad fundamentalmente en la coherencia y consistencia entre los fines de la organización, los valores y creencias personales, y la conducta individual ${ }^{5}$.

5. «And integrity, as noted above, is fundamentally a matter of coherence and consistency among organizacional aims, personal values and beliefs, and individual behavior» (Badaracco y Ellesworth, 1989:106). 
Para no dejarse impulsar en distintas direcciones, al directivo no le basta con su estilo, su carisma o una técnica de management profesional, pues se trata de su propia coherencia como persona, en una difícil y cotidiana búsqueda de integridad $^{6}$. A esto hay que añadir el efecto que la acción y las actitudes del líder producen en las demás personas y en el entorno, dado que en un mundo de incertidumbres él o ella se convierte en fuente de motivación y modelo de conducta. Esta certeza abre más aun el campo de la responsabilidad moral de su tarea.

Lo que está en juego es tan amplio que se hace necesaria esta tensión continua hacia la integridad para garantizar que nuestra vida siga siendo una vida humana. La integridad no es una condición que se alcanza de una vez por todas, pero curiosamente el querer ser íntegro ya es haber avanzado en su búsqueda, porque manifiesta la intención de que nuestros actos y actitudes broten coherentemente de un centro iluminado por los valores de la persona.

Cuando falta esta condición, las presiones ejercidas por las personas y circunstancias tienen una tarea más sencilla, porque la falta de integridad debilita a la persona. La capacidad de resistencia y la firmeza son proporcionales al grado de libertad; y el ejercicio de la libertad tiene que ver con la capacidad de manifestar ciertos valores, aun en circunstancias adversas.

Las presiones pueden responder a un contexto social deshecho por la falta de transparencia y de lealtad, en el que los

6. «It is a difficult daily quest for integrity» (Badaracco y Ellesworth, 1989: 209). actores se sientan impelidos a desconfiar de todos y a aprovechar las ventajas sin pensar en la justicia. Este panorama tiene una vida corta, pues las ventajas que ofrece el desequilibrio existirán hasta que nuevamente se logre el equilibrio. Lo que se emprende a la luz efímera de sacar ventaja de la debilidad del sistema está destinado a desaparecer.

Los apremios impulsan la búsqueda de resultados inmediatos, de decisiones oportunistas que no sólo repercuten negativamente en el entorno, reforzando la desconfianza, sino que también impiden los proyectos a largo plazo, para los cuales hace falta una capacidad de inserción en la realidad, con base en relaciones de cooperación con los demás actores. A pesar de ello, cada vez más, la calidad de una empresa se juzga en función de la perdurabilidad.

La despreocupación por la integridad logra que las presiones no encuentren resistencia e impide un verdadero ejercicio de la libertad, con el consecuente recorte de la capacidad creativa que le es propia. Esta afirmación parece contradecir la convicción de muchos de que la persona íntegra, así como la institución que hace de la integridad su identidad, jueguen en condición de inferioridad en un escenario de fuertes presiones contrarias a la integridad. Sin embargo, la realidad es otra: la presencia de integridad da a las personas y a las instituciones una mayor consistencia, lo que les permite mantenerse firme al mando de la propia existencia.

En este mismo sentido, Sharp Paine (2003) aconseja que se evalúe la capacidad gerencial según criterios múltiples, que integren también, en el mismo orden de importancia, criterios basados en 
valores. Los ejemplos analizados en su libro demuestran que la perdurabilidad de una empresa depende de su capacidad de respuesta más integral a las necesidades de la comunidad. Si se consideran todos los aspectos del proceso de producción y distribución de un bien, no se corre el riesgo de intervenir erróneamente en la vida comunitaria.

Es llamativo el caso del banco nigeriano GTB (Guaranty Trust Bank of Nigeria), que hace de la lucha contra la corrupción su bandera y su modus operandi. Sus comienzos no fueron fáciles y los primeros seis meses de pérdidas podrían haber sido ocultados con el fin de sobrevivir pero, a la luz de una coherencia interna, sus fundadores quisieron enfrentar con transparencia la dura realidad. Finalmente, esta actitud fue la que significó una buena percepción por parte de los inversionistas y los clientes. El mismo nivel de compromiso tanto en las capacidades profesionales como en las éticas significó una presencia diferente y promisoria en la comunidad.

Algo análogo se presenta en la actitud de la firma suiza Veillon, que compraba a terceros ciertas alfombras hechas a mano en algún lugar de Asia. Un día, su CEO Zwahlen, alertado por un programa de radio que denunciaba la existencia de trabajo infantil, quiso conocer las circunstancias en que se fabricaban las alfombras que ellos vendían, pues consideraba que la calidad de un servicio involucra también las condiciones en que ese servicio es producido. Sin embargo, sólo encontró respuestas evasivas. Su interés personal en no colaborar con trabajos en condiciones inhumanas y en no ser partícipe del flagelo del trabajo infantil, lo impulsó a seguir la ruta de las alfombras. El giro más decisivo de su investigación se lo dio su determinación de no dejar simplemente de comprar las alfombras fruto del trabajo infantil, sino de interesarse en encontrar una forma de revertir esa situación. Su integridad lo llevó a tomar la decisión de no ser parte del mercado que consume bienes producidos en condiciones inaceptables y, además, le dio la convicción de que debía intervenir activamente para cambiar esa realidad. Su decisión repercutió en la reputación de su empresa, aunque este no era su objetivo principal.

Esto es lo que Sharp Paine (2003) define cono center-driven leadership, es decir, la capacidad de liderazgo que integre los requerimientos financieros con los morales, como aspectos no separables, sin gravísimas consecuencias para los individuos y para las comunidades.

Parece que cada vez más la sociedad como un todo, inclusive en su dimensión globalizada, no está ya dispuesta a aceptar que algo sea rentable pero inmoral. Reconocer la capacidad de las empresas y de los directivos de influir en la calidad de vida de las comunidades implica reconocer, al mismo tiempo, la necesidad de la integridad personal e institucional para que, desde la tarea empresaria, surja una cultura favorable a una vida plenamente humana.

\section{Ideas para avanzar}

Una vez establecida la relevancia del tema de la integridad, tanto en la dimensión individual de las personas como en su dimensión social, y en la actividad de las empresas, el ulterior desarrollo de este concepto deberá seguir por lo menos dos derroteros: el del fundamento antropológico y el del estudio de campo. 
En el primer análisis debe asociarse el concepto de integridad a lo que es realmente el hombre, para lo cual, dada la complejidad de la realidad humana, será necesario referir cada aspecto, una vez analizado, a un centro operativo. Esto es, la voluntad iluminada por la inteligencia y orientada por valores que define, de alguna manera, lo que entendemos por integridad como condición interior de la persona. Estas aclaraciones servirán para distinguir la verdadera integridad de la rigidez y del fanatismo, pues la integridad guarda relación con la realidad y puede ser flexible, como lo es un árbol bien plantado en sus raíces.

Por otra parte, como ocurre con muchos conceptos filosófico-antropológicos, puede ser difícil encontrar una definición exacta de integridad. Sin embargo, generalmente, es menos difícil constatar que una persona es íntegra o no lo es, que existe una lucha por abrazar la integridad o no. Esta es la razón por la cual es oportuna una amplia investigación de campo, cuyo objetivo será identificar las características de una dirección de empresas en la que se lucha por preservar la integridad personal o, a la vez, en la que se trata de que toda la organización sea íntegra. Este tema es especialmente relevante en un contexto en el que se promueve actuar por valores, porque es negocio, o en el que el escepticismo mueve a plantear que no se puede ser honesto o correcto sin resignar beneficios económicos.
El estudio de campo se propone también identificar las presiones más frecuentes contrarias a la integridad a la que se encuentran sometidos los directivos, así como describir las estrategias exitosas para mantenerse firmes en sus convicciones, sin ser inflexibles. Disponer de datos empíricos sobre estas conductas y actitudes puede ser una contribución válida a promover una tarea directiva que sea capaz de hacer frente a las dificultades -grandes o chicas- sin perder el rumbo, que es siempre el bien común.

Además, estos conocimientos y el relato de las situaciones conflictivas bien resueltas echarán por tierra la convicción generalizada de que no se puede combatir la corrupción de una sociedad cuando ya está instalada en su cultura, porque será posible reconocer que las empresas también impactan -positiva o negativamente- en la cultura de una comunidad y pueden modificarla sustancialmente.

La tarea directiva que se preocupe por la integridad personal e institucional puede ser el elemento clave para reconstruir un ámbito de confianza entre los distintos actores del quehacer social, y puede ser el factor que permita de nuevo la cooperación en pos del bien de las personas y de la comunidad. 


\section{Referencias bibliográficas}

BADARACCO, J. y ELLESWORTH, R. 1989. Leadership and the quest for integrity. Boston: Harvard Business School Press.

BECKER, T. 1998. Integrity in organizations: Beyond honesty and conscientiousness. Academy of Management Review. Enero, vol. 23, n. ${ }^{\circ} 1$, págs. 154-161.

BENJAMIN, M. 1990. Splitting the difference: Compromise and integrity in ethics and politics. Lawrence, Kansas: University Press of Kansas.

BURBULES, N. C. 1992. The virtues of reasonableness. En: Buchmann M. y Floden, R. (editores). Philosophy of Education 1991. Normal, Ill.: Philosophy of Education Society, págs. 215-224.

CALHOUN, C. 1995. Standing for something. The Journal of Philosophy. Mayo, vol. 92, n. ${ }^{\circ}$, págs. 235-260.

CAMDESUSS, Michel. 1998. XX Congreso de la UNIAPAC (Unión Mundial de Empresarios Cristianos), Roma, oct.

CARTER, S. 1996. Integrity, Nueva York: Basic Books. 288 págs.

CHEN, A.; SAWYERS, R y WILLIAMS, P. 1997. Reinforcing ethical decision making through corporate culture. Journal of Business Ethics. Junio, vol. 16, n. ${ }^{\circ}$, págs. 855-865.

DEBELJUH, P. 2004. La conquista de las virtudes en la empresa. Buenos Aires: Temas grupo editorial.
DE BINGEN, Hildegarda. 1882. Liber divinorum operum (El libro de las obras divinas, 1163-74). Parte 1, visión 1. En Migne, J.P. (editor). Patrologiae cursus completus. Series latina. Vol. 197, cols. 739-1038. París, págs. 46-59.

ERICKSON, E. 1950. Childhood and society. Nueva York: W.W. Norton.

GRAHAM, J. 2001. Does integrity require moral goodness? Ratio. Setiembre, vol. 14, n. ${ }^{\circ}$, págs. 234-251.

HALFON, M. 1989. Integrity: A philosophical inquiry. Philadelphia: Temple University Press. 192 págs.

HAMPSHIRE, S. 1989. Innocence and experience. Cambridge: Harvard University Press.

HURSTHOUSE, R. 2000. On virtue ethics. Oxford: Oxford University Press. 288 págs.

MAY, L. 1996. The socially responsive self: Social theory and professional ethics. Chicago: The University of Chicago Press. 217 págs.

MC FALL, L. 1987. Integrity. Ethics. 98, págs. 5-20.

MELÉ, D. 1996. Actuación social de la empresa. Documento de Investigación n. ${ }^{\circ} 117$. Barcelona: IESE.

PAINE, L. 1997. Leadership, ethics and organizational integrity: A strategic perspective. Irwin, Chicago: McGraw-Hill. 
PETRICK, J. y QUINN, J. 2000. The integrity capacity construct and moral progress in business. Journal of Business Ethics. Enero, vol. 23, n. ${ }^{\circ}$, págs. 3-18.

SISON, A. 2003. The moral capital of leaders: Why virtue matters. Northampton, M.A.: Edward Elgar Publisher. 170 págs.

SOLOMON, R. 1999. Nuevas reflexiones acerca de las organizaciones de negocios: El éxito basado en la integridad de las personas. México: Oxford University Press. 129 págs.

1992. Ethics and excellence: Cooperation and integrity in business. (The Ruffin Series in Business Ethics). Nueva York: Orford University Press. 304 págs.
SHARP PAINE, L. 2003. Value shift: Why companies must merge social and financial imperatives to achieve superior performance. Nueva York: McGraw-Hill. 304 págs.

TAYLOR, C. 1989. Sources of the self: The making of the modern identity. Cambridge: Harvard University Press. 601 págs.

WADDOCK, S. 2003. A radical agenda for business in society. Chestnut Hill, M.A.: Boston College.

WERHANE, P. y FREEMAN, R. (editores). 1997. Blackwell Encyclopedic Dictionary of Business Ethics. Gran Bretaña: Blackwell Publishers. 701 págs. 